\title{
Observed Microphysical Characteristics of Stratiform and Convective Precipitation over an Inland Arid Region of the Qinghai-Tibet Plateau
}

\author{
Hongwei Xie ${ }^{1}$, Peichong Pan ${ }^{1}$, Haiyun Shi ${ }^{2,3, * \mathbb{D}}$, Ji Chen ${ }^{4}$ and Jinzhao Wang ${ }^{1,2,3}$ \\ 1 State Key Laboratory of Plateau Ecology and Agriculture, Qinghai University, Xining 810016, China; \\ 1986990054@qhu.edu.cn (H.X.); panfangqun@163.com (P.P.); qhdxwangjinzhao@163.com (J.W.) \\ 2 State Environmental Protection Key Laboratory of Integrated Surface Water-Groundwater Pollution Control, \\ School of Environmental Science and Engineering, Southern University of Science and Technology, \\ Shenzhen 518055, China \\ 3 Guangdong Provincial Key Laboratory of Soil and Groundwater Pollution Control, School of Environmental \\ Science and Engineering, Southern University of Science and Technology, Shenzhen 518055, China \\ 4 Department of Civil Engineering, The University of Hong Kong, Hong Kong 999077, China; jichen@hku.hk \\ * Correspondence: shihy@sustech.edu.cn; Tel.: +86-755-8801-8870
}

Received: 18 July 2020; Accepted: 13 August 2020; Published: 16 August 2020

\begin{abstract}
This study analyzed the microphysical characteristics of stratiform and convective precipitation over an inland arid region of Qinghai-Tibet Plateau in summer for the first time. The observed precipitation data were from the OTT Parsivel ${ }^{2}$ laser raindrop spectrometer and the raindrop size distribution can be described by a gamma distribution and a general exponential distribution. The results indicate that: (1) compared to the exponential distribution, the gamma distribution is the better function with which to describe the raindrop size distribution in this region; (2) the raindrop sizes are mainly below $1 \mathrm{~mm}$, and the raindrop sizes which contribute most to the rainfall intensity are below $2 \mathrm{~mm}$ for stratiform precipitation and convective precipitation; (3) the mean values of microphysical parameters, e.g., rainfall intensity, radar reflectivity factor, and liquid water content, are higher for convective precipitation than stratiform precipitation; and (4) the standard $Z-R$ relationship underestimates the radar reflectivity factor in this region. Overall, the obtained results will enhance our understanding and facilitate future studies regarding the microphysical characteristics of precipitation in such regions. For example, the obtained $Z-R$ relationship can be a reference for estimating the radar reflectivity factor in this region with higher accuracy.
\end{abstract}

Keywords: stratiform precipitation; convective precipitation; raindrop size distribution; microphysical characteristics; $Z-R$ relationship; Qinghai-Tibet plateau

\section{Introduction}

As a common meteorological term, precipitation is of great importance to a variety of fields, such as water resource management, agriculture, and ecological environment assessing [1-6]. A better understanding of the microphysical processes of precipitation can be obtained through analyzing the raindrop size distribution (DSD) and the related microphysical parameters. The raindrop size distribution is expressed as the number of raindrops per unit size interval per unit volume in space [7]. From the perspective of cloud microphysics, the raindrop size distribution is determined by various mechanisms in nature [8]. The raindrop size distribution not only shows the spatial and temporal changes of precipitation, but is also directly related to the microphysical characteristics of precipitation, such as evaporation, absorption and conversion rate [9]. In the early years, manual sampling methods were used for raindrop size distribution analysis, such as the kinetic method [10] and stain method [11]. 
However, the disadvantages of these methods are obvious, i.e., low measurement accuracy, heavy workload, high cost and cumbersome calculation. Along with the development of photoelectric measuring technology, laser raindrop spectrometers have been widely used, and relevant studies on raindrop size distribution have been conducted [12-15].

Microphysical processes differ according to the type of precipitation, stratiform or convective, and thus, it is necessary to develop effective methods for classifying them. For example, stratiform precipitation can be identified by a "bright band" in cloud. Gamache and Houze [16] used the radar reflectivity factor of precipitation to classify different types of precipitation, and they concluded that convective precipitation appears when the radar reflectivity factor is higher than $38 \mathrm{dBz}$. Johnson and Hamilton [17] used the rainfall intensity to classify different types of precipitation, and they concluded that convective precipitation appears when the rainfall intensity is larger than $0.1 \mathrm{~mm} \cdot \mathrm{min}^{-1}$. In addition, stratiform precipitation and convective precipitation can be distinguished using other criteria, e.g., characteristic diameter (parameter indicating precipitation particle size), standard deviation, and rainfall intensity [18-20]. Based on the methods in the studies of Bringi et al. [18] and Marzano et al. [20], Chen et al. [21] proposed a new method which uses the standard deviation of rain intensity from the consecutive 10-min samples during a certain precipitation process. By considering the method proposed by Chen et al. [21] as the integrated one, it was selected for classifying different types of precipitation in this study.

Furthermore, regarding $Z$ as the radar reflectivity factor and $R$ as the rainfall intensity, the $Z-R$ relationship has been widely used for precipitation estimation [22-28]. For example, Chandrasekar and Bringi [23] pointed out that the uncertainty of the $Z-R$ relationship is closely related to the changing characteristics of raindrop size distribution. Hasan et al. [27] developed an error model to investigate the uncertainty in point rain gauge networks and its effects on bias correction in the $Z-R$ relationship. Fang et al. [28] recalculated the $Z-R$ relationship over the Yangtze-Huaihe River basin in order to predict severe weather more accurately. However, to the best of our knowledge, there are still very few studies on this topic over the Qinghai-Tibet Plateau [29]. The characteristics of raindrop size distribution over Nagqu in the Tibetan Plateau and Yangjing in southern China were studied in [29], and our research is mainly aimed at the inland arid areas of the Qinghai-Tibet Plateau. Therefore, it is of great importance to provide a much clearer understanding of the $Z-R$ relationship over this region.

Plateau mountainous regions in the western China are particularly sensitive to climate change, bringing serious disturbances to local ecosystem [30,31]. For example, more precipitation may cause floods and less precipitation may cause droughts. Several studies $[3,31-33]$ have shown increasing trends in annual precipitation and precipitation extremes over the Qinghai-Tibet Plateau. However, locally, there are still few studies over the inland arid region of the Qinghai-Tibet Plateau. Since precipitation is one of the basic components of the hydrological cycle, to investigate the microphysical characteristics of precipitation for such regions has both scientific and practical significances. As a result, based on the precipitation data (i.e., raindrop size distribution) obtained from the raindrop spectrometer, this study aimed to report new findings in the following aspects, including (1) the appropriate distribution with which to describe the raindrop size distribution in the designated region; (2) the contributions of raindrops with different sizes to the microphysical parameters of precipitation; and (3) the changing features of various microphysical parameters (i.e., rainfall intensity, liquid water content, and radar reflectivity factor) of precipitation. Since this is the first study on the microphysical characteristics of different precipitation types over an inland region of the Qinghai-Tibet Plateau, the obtained results will be of great value for researchers to inspect the effects of artificial weather modification and conduct quantitative assessments of precipitation. It is also useful for managers to make better decisions on related water projects in the future for such regions. 


\section{Materials and Methods}

\subsection{Study Area}

The study area, Delhi, is located in the inland region of the Qinghai-Tibet Plateau in western China, i.e., in the northeastern part of Qaidam Basin (see Figure 1). This region has a highland continental climate with year-round drought and little rain. The annual average temperature is about $4.5^{\circ} \mathrm{C}$, and the average annual precipitation is about $200 \mathrm{~mm}$. The mean elevation of this region is over $2800 \mathrm{~m}$. In addition, this region lies in the temperate zone, mainly dominated by a plateau monsoon climate [34]. Normally, most of the annual precipitation occurs in the wet season from May to October [31,32].

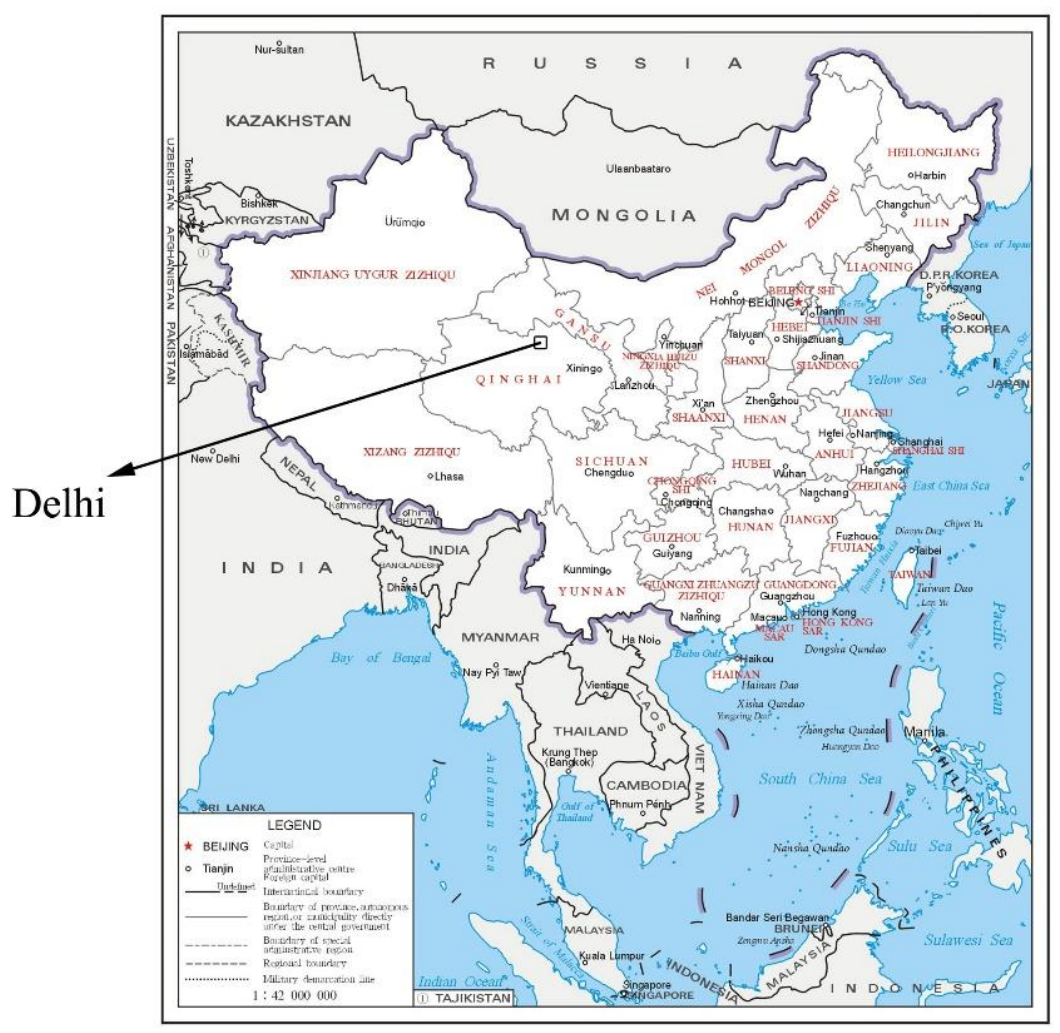

Figure 1. Map of China showing the study area.

\subsection{Research Data}

The precipitation data from June 2019 to September 2019 were collected by an OTT Parsivel ${ }^{2}$ laser raindrop spectrometer (see Figure 2). This equipment is produced by OTT Company in Germany. According to the manufacturer of OTT Parsivel ${ }^{2}$ (www.ott.com), OTT Parsivel ${ }^{2}$ is a laser-based optical system for complete and reliable measurement of all types of precipitation. The transmitter unit of the sensor generates a flat, horizontal beam of light that the receiver unit converts to an electrical signal. This signal changes whenever a hydrometeor falls through the beam anywhere within the measuring area of $54 \mathrm{~cm}^{2}$. The degree of dimming is a measure of the size of the hydrometeor, and the fall velocity is derived from the extinction signal duration. Its measurement interval is $1 \mathrm{~min}$, and we can define the data in $1 \mathrm{~min}$ as a sample. Moreover, it subdivides the measured particles into 32 classes in diameter and the particles speed. The measurement accuracy for liquid precipitation meets the WMO (World Meteorological Organization) recommendation of $\pm 5 \%$ in the intensity range of 0.001 to $1200 \mathrm{~mm} / \mathrm{h}$. For liquid precipitation, the measurement range of particle size is from $0.2 \mathrm{~mm}$ to $5 \mathrm{~mm}$; for solid precipitation, the measurement range of particle size is from $0.2 \mathrm{~mm}$ to $25 \mathrm{~mm}$. In addition, deformation occurs when raindrops fall. Therefore, raindrop deformation has been considered and treated in the design of this equipment, and the output data are obtained by correcting the deformation 
of the particles [35-37]. Class $1(0-0.125 \mathrm{~mm})$ and class $2(0.125-0.25 \mathrm{~mm})$ are not evaluated using the OTT Parsivel ${ }^{2}$ since they are outside the measurement range of this equipment. Therefore, the data from the first two channels (i.e., particle size from 0 to $0.25 \mathrm{~mm}$ ) were not used in this study [38]. According to the study of Tokay and Bashor [39], some data, e.g., data with the particle number of less than 10 , would be judged as noise and be deleted directly. Since the maximum measurable particle size of this equipment is $5 \mathrm{~mm}$ for liquid precipitation, the actual measurement range of raindrop size was from $0.25 \mathrm{~mm}$ to $5 \mathrm{~mm}$ in this study.

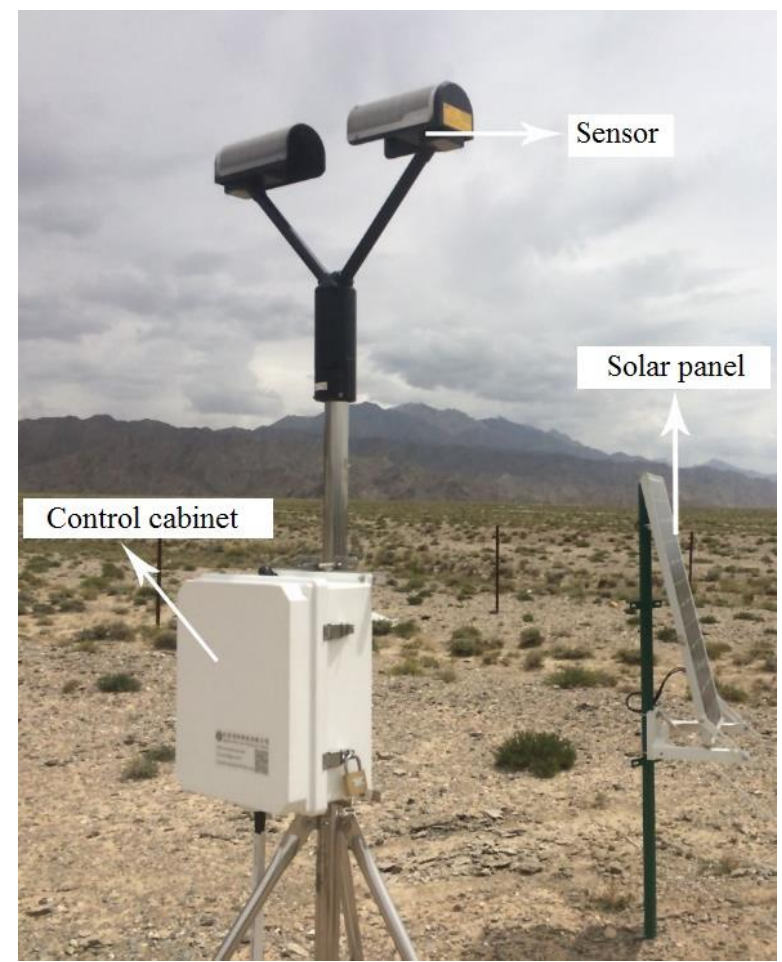

Figure 2. The OTT Parsivel ${ }^{2}$ laser raindrop spectrometer.

\subsection{Methods}

As previously introduced, various methods can be used to classify different types of precipitation [16,18,20,21]. Generally, three types of precipitation, i.e., stratiform precipitation, convective precipitation, and mixed convective-stratiform precipitation, can be defined based on radar echo characteristics and rainfall intensity. Based on raindrop spectrometer data, the method proposed by Chen et al. [21] was adopted in this study, and different types of precipitation were classified by the standard deviation of rain intensity from the consecutive 10 min samples during each precipitation event. The detailed criterion is as follows:

$$
\left\{\begin{array}{l}
0.5 \mathrm{~mm} / \mathrm{h} \leq R_{\max }<5 \mathrm{~mm} / \mathrm{h} \text { and } \sigma \leq 1.5 \mathrm{~mm} / \mathrm{h} \text {, stratiform precipitation } \\
R_{\max } \geq 5 \mathrm{~mm} / \mathrm{h} \text { and } \sigma>1.5 \mathrm{~mm} / \mathrm{h}, \text { convective precipitation } \\
\text { otherwise, mixed convective - stratiform precipitation }
\end{array}\right.
$$

where $R_{\max }$ is the maximum rainfall intensity $(\mathrm{mm} / \mathrm{h})$, and $\sigma$ is the standard deviation $(\mathrm{mm} / \mathrm{h})$.

In this study, by examining all the data samples, 29 precipitation events in summer were selected from the observed precipitation data during the study period (i.e., from June 2019 to September 2019) to meet the measurement requirement. Based on Equation (1), 18 precipitation events among them have stratiform precipitation, while the other 8 precipitation events have convective precipitation (see Table A1 for details). Mixed convective-stratiform precipitation will not be discussed because only 3 precipitation events were found for this type of precipitation. 
According to previous studies [12,40-42], various distribution functions, such as gamma distribution, general distribution, and lognormal distribution, can be fitted to the raindrop size distribution. In this study, the gamma distribution and the exponential distribution, which are both widely used, were adopted for fitting the observed raindrop size distribution in this region. The general form of gamma distribution is given as follows:

$$
N(D)=N_{0} D^{\mu} \exp (-\lambda D)
$$

where $D$ is the raindrop size $(\mathrm{mm}), N(D)$ is the number of raindrops in unit volume and interval $\left(\mathrm{m}^{-3} \mathrm{~mm}^{-1}\right), N_{0}$ is a concentration parameter $\left(\mathrm{m}^{-3} \mathrm{~mm}^{-1-\mu}\right), \mu$ is the shape factor, and $\lambda$ is the slope parameter $\left(\mathrm{mm}^{-1}\right)$. It is worth noting that Equation (2) will turn into the general exponential distribution when $\mu=0$.

The meaning of each microphysical quantity and its formula is shown in Table 1 , where $D_{i}$ is the diameter of the raindrop corresponding to the $i$-th scale channel, $N\left(D_{i}\right)$ is the particle number concentration corresponding to the scale channel, and $\Delta D_{i}$ is the width of the scale channel.

Table 1. Definition of some variables in this study.

\begin{tabular}{|c|c|c|}
\hline Variable & Formulate & Physics Meaning \\
\hline $\begin{array}{l}\text { Total raindrop concentration, } \\
N_{T}\left(\mathrm{~m}^{-3}\right)\end{array}$ & $N_{T}=\sum_{i=1}^{32} N\left(D_{i}\right) \Delta D_{i}$ & $\begin{array}{l}\text { Total number of particles per } \\
\text { unit volume }\end{array}$ \\
\hline $\begin{array}{l}\text { Rainfall intensity, } \\
R(\mathrm{~mm} / \mathrm{h})\end{array}$ & $R=\frac{6 \pi}{10^{4}} \sum_{i=1}^{32} D_{i}{ }^{3} V_{i} N\left(D_{i}\right) \Delta D_{i}$ & Precipitation per unit of time \\
\hline $\begin{array}{l}\text { Liquid water content, } \\
W\left(\mathrm{~g} / \mathrm{m}^{3}\right)\end{array}$ & $W=\frac{\pi}{6000} \sum_{i=1}^{32} D_{i}^{3} N\left(D_{i}\right) \Delta D_{i}$ & Total particle mass per unit volume \\
\hline $\begin{array}{l}\text { Radar reflectivity factor, } \\
\mathrm{Z}\left(\mathrm{mm}^{6} / \mathrm{m}^{3}\right)\end{array}$ & $Z=\sum_{i=1}^{32} D_{i}^{6} N\left(D_{i}\right) \Delta D_{i}$ & $\begin{array}{l}\text { Total particle retroreflective } \\
\text { cross-sections per unit volume }\end{array}$ \\
\hline $\begin{array}{l}\text { Mean diameter, } \\
D_{1}(\mathrm{~mm})\end{array}$ & $D_{1}=\sum_{i=1}^{32} D_{i} N\left(D_{i}\right) / \sum_{i=1}^{32} N\left(D_{i}\right)$ & $\begin{array}{l}\text { Average diameter of all particles in a } \\
\text { unit volume }\end{array}$ \\
\hline $\begin{array}{l}\text { Root mean square diameter, } \\
D_{2}(\mathrm{~mm})\end{array}$ & $D_{2}=\sqrt{\sum_{i=1}^{32} D_{i}^{2} N\left(D_{i}\right) / \sum_{i=1}^{32} N\left(D_{i}\right)}$ & $\begin{array}{l}\text { Its square indicates the average } \\
\text { cross section of the raindrops }\end{array}$ \\
\hline $\begin{array}{l}\text { Root mean cube diameter, } \\
D_{3}(\mathrm{~mm})\end{array}$ & $D_{3}=\sqrt[3]{\sum_{i=1}^{32} D_{i}^{3} N\left(D_{i}\right) / \sum_{i=1}^{32} N\left(D_{i}\right)}$ & $\begin{array}{l}\text { Its cube can indicate the average } \\
\text { volume or mass of the raindrops }\end{array}$ \\
\hline $\begin{array}{l}\text { Mass weighted diameter, } \\
D_{m}(\mathrm{~mm})\end{array}$ & $D_{m}=\sum_{i=1}^{32} \rho D_{i}^{4} N\left(D_{i}\right) \Delta D_{i} / \sum_{i=1}^{32} \rho D_{i}^{3} N\left(D_{i}\right) \Delta D_{i}$ & $\begin{array}{l}\text { Average diameter of the weighted } \\
\text { mass of all particles in a unit volume } \\
\text { relative to the total mass of } \\
\text { the particles }\end{array}$ \\
\hline
\end{tabular}

\section{Results and Discussion}

\subsection{Raindrop Size Distribution}

In this study, the curve fitting tool called cftool by least squares in MATLAB was used for analysis. The toolbox can provide rich fitting algorithms that are easy to use and can realize a variety of linear and nonlinear function fitting. Figure 3 shows the fitting results with $95 \%$ confidence interval of the mean raindrop size distribution for stratiform precipitation and convective precipitation, respectively. Since the $\mu$ values are larger than 0 , the curves in Figure 3 are both upward. Unimodal structures were observed for both of the two types of precipitation, and the spectral widths (i.e., difference between the maximum particle size and the minimum particle size) were $3.94 \mathrm{~mm}$ and $4.69 \mathrm{~mm}$ for stratiform precipitation and convective precipitation, respectively. With reference to the maximum raindrop concentration, it was $1473.49 \mathrm{~m}^{-3} \mathrm{~mm}^{-1}$ for convective precipitation, which was larger than that for stratiform precipitation (i.e., $609.26 \mathrm{~m}^{-3} \mathrm{~mm}^{-1}$ ). Therefore, the increase of $N_{0}$ is closely related with the increase of the maximum raindrop concentration. In addition, the slope parameter (i.e., $\lambda$ ) 
increases when the type of precipitation changes from stratiform precipitation (i.e., 11.41) to convective precipitation (i.e., 12.48). The steeper slope of convective precipitation is mainly caused by the more intense changes inside clouds.
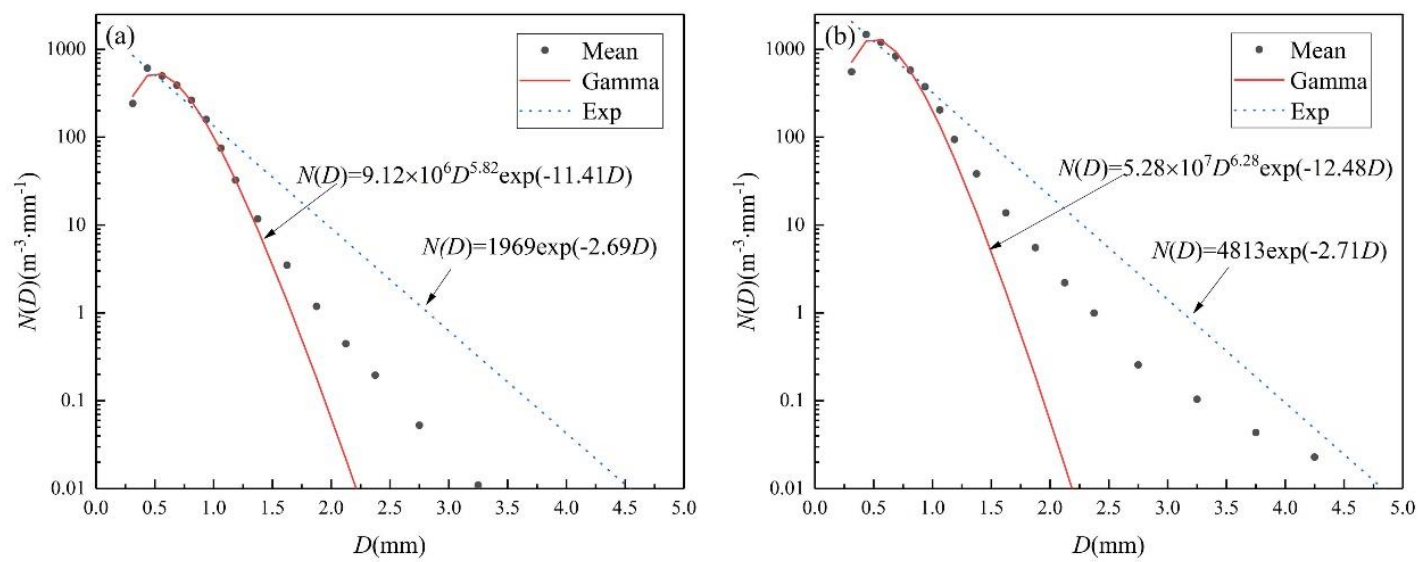

Figure 3. Fitting results of the mean raindrop size distribution for all the precipitation events from (a) stratiform precipitation and (b) convective precipitation. (Mean: the mean raindrop size distribution; Gamma: the gamma distribution; Exp: the exponential distribution).

For stratiform precipitation, the coefficients of determination for the fitting curves from the gamma distribution and the exponential distribution were 0.99 and 0.97 , respectively; the average relative errors were $10.15 \%$ and $42.06 \%$ (see Table 2), respectively; and the relevant root mean square errors were 10.84 and 27.11, respectively. The results indicate that gamma distribution is the better function to describe the raindrop size distribution for stratiform precipitation in this region. Similar results were obtained for convective precipitation; i.e., the coefficients of determination were 0.97 and 0.97 ; the average relative errors were $15.12 \%$ and $39.74 \%$, respectively; and the root mean square errors were 63.17 and 64.25 , for the gamma distribution and the exponential distribution, respectively. It is worth noting that raindrops with relatively smaller sizes contribute more to the rainfall intensity than raindrops with relatively larger sizes (see Section 3.2 for details). Known from Figure 3, the errors of fitting for raindrops with relatively smaller sizes (e.g., $D<2.5 \mathrm{~mm}$ ) are lower using gamma distribution. For the total raindrop concentration, raindrops with diameters between the first point $(D=0.312 \mathrm{~mm})$ and second point $(D=0.437 \mathrm{~mm})$ in the mean distribution in Figure 3 account for $36.94 \%$ and $37.26 \%$ of the total contribution for stratiform precipitation and convective precipitation, respectively. Therefore, the point $(D=0.312 \mathrm{~mm})$ below the maximum $(D=0.437 \mathrm{~mm})$ in $N(D)$ is critical for the fit to gamma distribution. In addition, it can be calculated from the mean raindrop concentration value and the fitted raindrop concentration value of the point between 0.2 and $1 \mathrm{~mm}$, and the average relative errors of raindrops with diameters of $0.2-1 \mathrm{~mm}$ for stratified precipitation were $9.93 \%$ and $38.80 \%$ for the gamma distribution and the exponential distribution, respectively; for convective precipitation, they were $14.43 \%$ and $36.99 \%$. As is known from Section 3.2, raindrops with diameters of $0.25-1 \mathrm{~mm}$ contribute most to the raindrop concentration and number of particles. Therefore, it is concluded that the gamma distribution can better describe the raindrop size distribution in this region.

Table 2. Values of the statistical fit and errors.

\begin{tabular}{ccccccc}
\hline \multirow{2}{*}{ Distribution } & \multicolumn{3}{c}{ Stratiform Precipitation } & \multicolumn{3}{c}{ Convective Precipitation } \\
\cline { 2 - 7 } & $\boldsymbol{R}^{\mathbf{2}}$ & $\boldsymbol{R M S E}$ & $\boldsymbol{A R E}$ & $\boldsymbol{R}^{\mathbf{2}}$ & $\boldsymbol{R M S E}$ & $\boldsymbol{A R E}$ \\
\hline Gamma & 0.9958 & 10.84 & $10.15 \%$ & 0.9742 & 63.17 & $15.12 \%$ \\
Exponential & 0.9728 & 27.11 & $42.06 \%$ & 0.9714 & 64.25 & $39.74 \%$ \\
\hline
\end{tabular}




\subsection{Contributions of Raindrops with Different Sizes to Microphysical Parameters}

In this study, raindrops with different sizes were divided into four grades, i.e., $0.25-1 \mathrm{~mm}, 1-2 \mathrm{~mm}$, 2-3 mm, and $>3 \mathrm{~mm}$, respectively. Then, their contributions to a variety of microphysical parameters (i.e., total raindrop concentration, number of raindrops, rainfall intensity, and liquid water content) were calculated, and the relevant results are shown in Table 3. Overall, raindrops with diameters of $0.25-1 \mathrm{~mm}$ contributed most to all the four selected microphysical parameters. However, for each microphysical parameter, there were certain differences. For total raindrop concentration, raindrops with diameters of $0.25-1 \mathrm{~mm}$ accounted for over $90 \%$ of the total contribution for both stratiform precipitation and convective precipitation, while raindrops with diameters of larger than $2 \mathrm{~mm}$ accounted for less than $1 \%$. That indicates that the majority of raindrops in this region have relatively smaller sizes (i.e., $D<2 \mathrm{~mm}$ ). The result of liquid water content was basically consistent with that of total raindrop concentration. By contrast, for number of raindrops and rainfall intensity, the situations were different for stratiform precipitation and convective precipitation. For stratiform precipitation, similar results were found as those of total raindrop concentration and liquid water content, whereas for convective precipitation, the contributions of raindrops with diameters of 1-2 mm were comparable to those of raindrops with diameters of less than $1 \mathrm{~mm}$. As a result, it can be concluded that the raindrop sizes of less than $2 \mathrm{~mm}$ contribute most to the rainfall intensity of stratiform and convective precipitation.

Table 3. Contributions of raindrops with different sizes to microphysical parameters for precipitation from (a) stratiform precipitation and (b) convective precipitation. Note: $N_{T}$ (total raindrop concentration), $n_{T}$ (total number of particles), $R$ (rainfall intensity), $W$ (liquid water content).

\begin{tabular}{cccccccccc}
\hline (a) & $\boldsymbol{N}_{\boldsymbol{T}} \mathbf{( \% )}$ & $\boldsymbol{n}_{\boldsymbol{T}} \mathbf{( \% )}$ & $\boldsymbol{R} \mathbf{( \% )}$ & $\boldsymbol{W} \mathbf{( \% )}$ & $\mathbf{( b )}$ & $\boldsymbol{N}_{\boldsymbol{T}} \mathbf{( \% )}$ & $\boldsymbol{n}_{\boldsymbol{T}}(\mathbf{\%})$ & $\boldsymbol{R} \mathbf{( \% )}$ & $\boldsymbol{W}(\mathbf{\%})$ \\
\hline $0.25-1 \mathrm{~mm}$ & 93.84 & 88.29 & 67.36 & 66.76 & $0.25-1 \mathrm{~mm}$ & 92.25 & 85.35 & 55.05 & 57.49 \\
$1-2 \mathrm{~mm}$ & 6.1 & 11.51 & 32.24 & 30.71 & $1-2 \mathrm{~mm}$ & 7.80 & 14.22 & 42.71 & 36.62 \\
$2-3 \mathrm{~mm}$ & 0.06 & 0.19 & 0.40 & 2.23 & $2-3 \mathrm{~mm}$ & 0.14 & 0.39 & 2.13 & 4.18 \\
$>3 \mathrm{~mm}$ & 0 & 0 & 0 & 0.30 & $>3 \mathrm{~mm}$ & 0.01 & 0.04 & 0.12 & 1.71 \\
\hline
\end{tabular}

\subsection{Characteristics of Microphysical Parameters}

In this study, characteristics of microphysical parameters were analyzed based on the values derived from the mean raindrop size distribution for stratiform precipitation and convective precipitation. Table 4 lists the mean values of several microphysical parameters.

Table 4. The mean values of microphysical parameters. Note: $D_{1}$ (mean diameter), $D_{2}$ (root mean square diameter), $D_{3}$ (root mean cube diameter), $N_{T}$ (total raindrop concentration), $R$ (rainfall intensity), $W$ (liquid water content), $Z$ (radar reflectivity factor).

\begin{tabular}{ccccccccc}
\hline Type & $\begin{array}{c}\boldsymbol{D}_{\mathbf{1}} \\
(\mathbf{m m})\end{array}$ & $\begin{array}{c}\boldsymbol{D}_{\mathbf{2}} \\
\mathbf{( m m )}\end{array}$ & $\begin{array}{c}\boldsymbol{D}_{\mathbf{3}} \\
(\mathbf{m m})\end{array}$ & $\begin{array}{c}\boldsymbol{D}_{\boldsymbol{m}} \\
(\mathbf{m m})\end{array}$ & $\begin{array}{c}\boldsymbol{N}_{\boldsymbol{T}} \\
\left(\mathbf{m m}^{-3}\right)\end{array}$ & $\begin{array}{c}\boldsymbol{R} \\
(\mathbf{m m} / \mathbf{h})\end{array}$ & $\begin{array}{c}W \\
\left(\mathbf{g} / \mathbf{m}^{\mathbf{3}}\right)\end{array}$ & $\begin{array}{c}\mathbf{Z} \\
(\mathbf{d B z})\end{array}$ \\
\hline Stratiform precipitation & 0.6108 & 0.6494 & 0.6899 & 0.9447 & 288.04 & 0.59 & 0.0535 & 21.70 \\
Convective precipitation & 0.6155 & 0.6585 & 0.7055 & 1.0724 & 680.31 & 2.00 & 0.1416 & 29.50 \\
\hline
\end{tabular}

Based on the results shown in Table 4, it is clear that all the values for stratiform precipitation are lower than the corresponding values for convective precipitation. The characteristic diameter of the stratiform precipitation is smaller than that of the convective precipitation due to the larger proportion of large diameter sizes in the convective precipitation. Meanwhile, according to the formula (see Table 1), the increase in particles will also lead to an increase in liquid water content. With reference to single events, three precipitation events for stratiform precipitation (i.e., corresponding to numbers 2, 14 and 15 in Table A1) and three precipitation events for convective precipitation (i.e., corresponding to numbers 20, 21 and 25 in Table A1) were randomly selected as typical representatives in order to 
analyze the changing features of these microphysical parameters across time, as shown in Figure 4 . Among them, Figure $4 \mathrm{a}-\mathrm{c}$ shows stratiform precipitation and Figure $4 \mathrm{~d}-\mathrm{f}$ shows for convective precipitation. Furthermore, it is clear that the variations of these microphysical parameters present a multi-peak structure for precipitation events with stratiform precipitation (see Figure $4 \mathrm{a}-\mathrm{c}$ ) and a few-peak structure for precipitation events with convective precipitation (see Figure $4 \mathrm{~d}-\mathrm{f}$ ). In this study, an overall analysis of other events was conducted, and it was found that their trends were basically the same. However, due to paper length reason, they were not listed one by one, and only the six randomly selected events were further analyzed to investigate the changing feature of a single precipitation event.
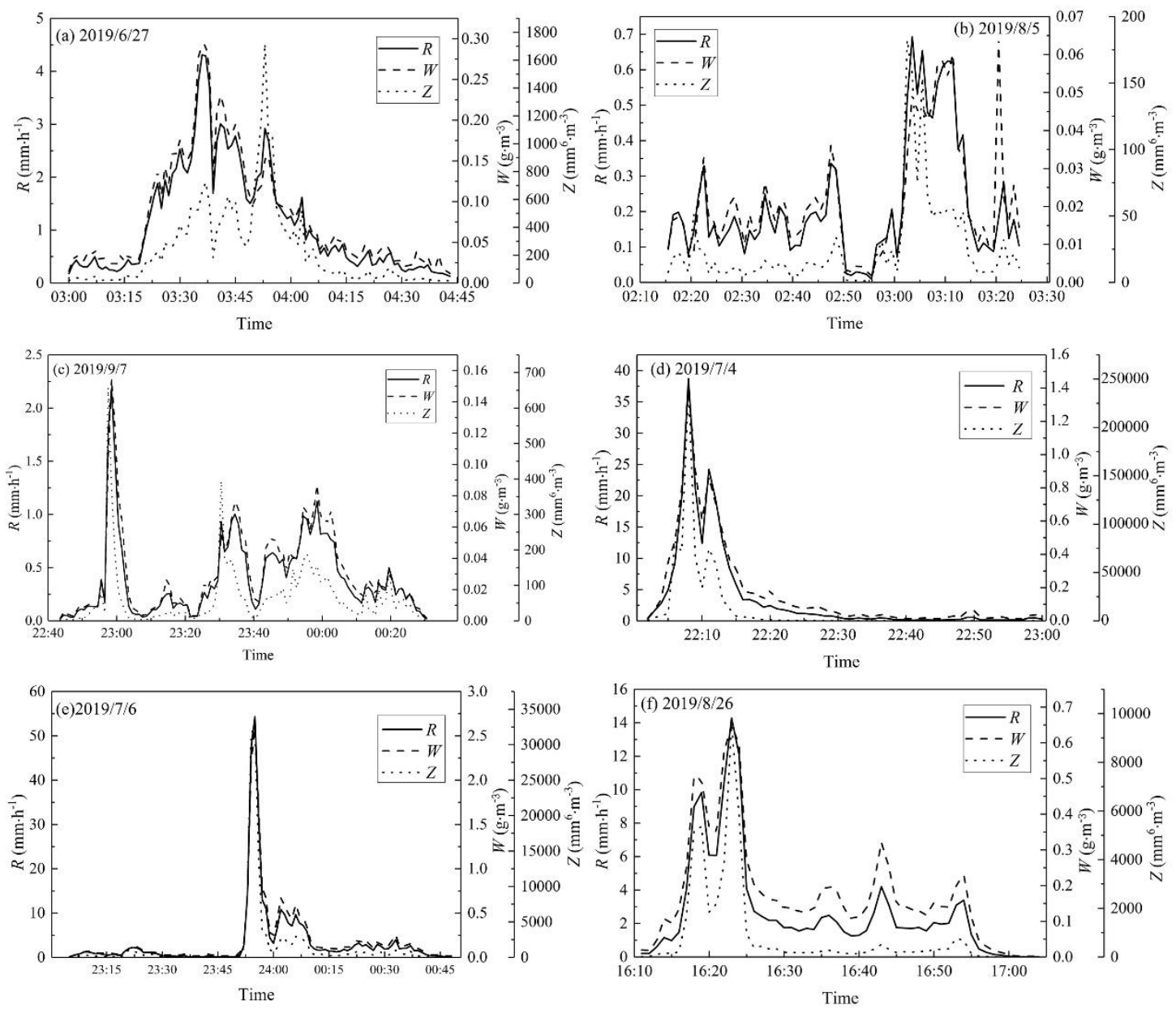

Figure 4. Changes of microphysical parameters (i.e., $R, W$, and $Z$ ) over time for precipitation events of (a) 2019/6/27 3:00-4:43, (b) 2019/8/5 2:16-3:25, (c) 2019/9/7 22:44-2019/9/8 00:31, (d) 2019/7/4 22:02-23:00,

(e) 2019/7/6 23:05-2019/7/7 00:48, and (f) 2019/8/26 16:11-17:04.

The first precipitation event (Figure 4a) occurred on 27 June 2019, and the spectral width was $2.94 \mathrm{~mm}$. The raindrop concentration reached the maximum value of $3.41 \log _{10}\left(\mathrm{~m}^{-3} \mathrm{~mm}^{-1}\right)$ at $3: 31$ (see Figure 5a), and the corresponding class was $0.437 \mathrm{~mm}$ in diameter, because the class had the largest number of particles. Additionally, the rainfall intensity reached the maximum value of $4.31 \mathrm{~mm} / \mathrm{h}$. The second precipitation event (Figure 4b) occurred on August 5, 2019, and lasted for $70 \mathrm{~min}$. The spectral width was $2.06 \mathrm{~mm}$. At the beginning of this event, the width of the distribution gradually increased, and the maximum rainfall intensity reached $0.69 \mathrm{~mm} / \mathrm{h}$ at 3:04 local time (same later). The radar reflectivity factor also reached the maximum value (i.e., $182.47 \mathrm{~mm}^{6} / \mathrm{m}^{3}$ ); the corresponding class diameter was $0.437 \mathrm{~mm}$. The maximum raindrop concentration (i.e., $3.28 \log _{10}\left(\mathrm{~m}^{-3} \mathrm{~mm}^{-1}\right)$ ) appeared after $5 \mathrm{~min}$, (see Figure $5 \mathrm{~b}$ ). At that time, the corresponding rainfall intensity was 
$0.61 \mathrm{~mm} / \mathrm{h}$. The third precipitation event (Figure 4c) occurred on September 7, 2019, and lasted for $105 \mathrm{~min}$. Thirteen minutes after the start of precipitation, the rain intensity, radar reflectivity factor, and liquid water content all reached their maximum values, which were $2.19 \mathrm{~mm} / \mathrm{h}, 657.66 \mathrm{~mm}^{6} / \mathrm{m}^{3}$, and $0.15 \mathrm{~g} / \mathrm{m}^{3}$, respectively. The corresponding raindrop concentration also reached a maximum value (i.e., $3.15 \log _{10}\left(\mathrm{~m}^{-3} \mathrm{~mm}^{-1}\right)$ ) (see Figure $5 \mathrm{c}$ ), and the corresponding class was $0.437 \mathrm{~mm}$ in diameter. The fourth precipitation event (Figure 4d) occurred on July 4, 2019, and the spectral width was $5.69 \mathrm{~mm}$. Six minutes after it began to rain, rainfall intensity (i.e., $38.69 \mathrm{~mm} / \mathrm{h}$ ) and raindrop concentration (i.e., $3.48 \log _{10}\left(\mathrm{~m}^{-3} \mathrm{~mm}^{-1}\right)$ ) reached the maximum values (see Figure $5 \mathrm{~d}$ ); the corresponding was $0.562 \mathrm{~mm}$ class in diameter. Then, the second peak of rainfall intensity (i.e., $24.19 \mathrm{~mm} / \mathrm{h}$ ) appeared eight minutes later, and the corresponding raindrop concentration was $0.55-3.26 \log _{10}\left(\mathrm{~m}^{-3} \mathrm{~mm}^{-1}\right)$. After that, raindrop concentration began to decrease. The fifth precipitation event (Figure 4e) occurred on July 6, 2019, and lasted for $99 \mathrm{~min}$. The spectral width was $3.94 \mathrm{~mm}$. The rain intensity reached its maximum (i.e., $54.32 \mathrm{~mm} / \mathrm{h}$ ) at 23:55. At this time, the radar reflectivity factor and liquid water content also reached their maxima (i.e., $32726.53 \mathrm{~mm}^{6} / \mathrm{m}^{3}$ and $2.59 \mathrm{~g} / \mathrm{m}^{3}$ ). The maximum raindrop concentration was $3.63 \log _{10}\left(\mathrm{~m}^{-3} \mathrm{~mm}^{-1}\right.$ ) (see Figure 5e), and the corresponding class was $0.437 \mathrm{~mm}$ in diameter. The sixth precipitation event (Figure 4f) occurred on 26 August 2019, and lasted for 53 min. The rain intensity, radar reflectivity factor, and liquid water content all reached their maximum values at $16: 23$, which were $14.28 \mathrm{~mm} / \mathrm{h}, 955.13 \mathrm{~mm}^{6} / \mathrm{m}^{3}$, and $0.65 \mathrm{~g} / \mathrm{m}^{3}$, respectively.
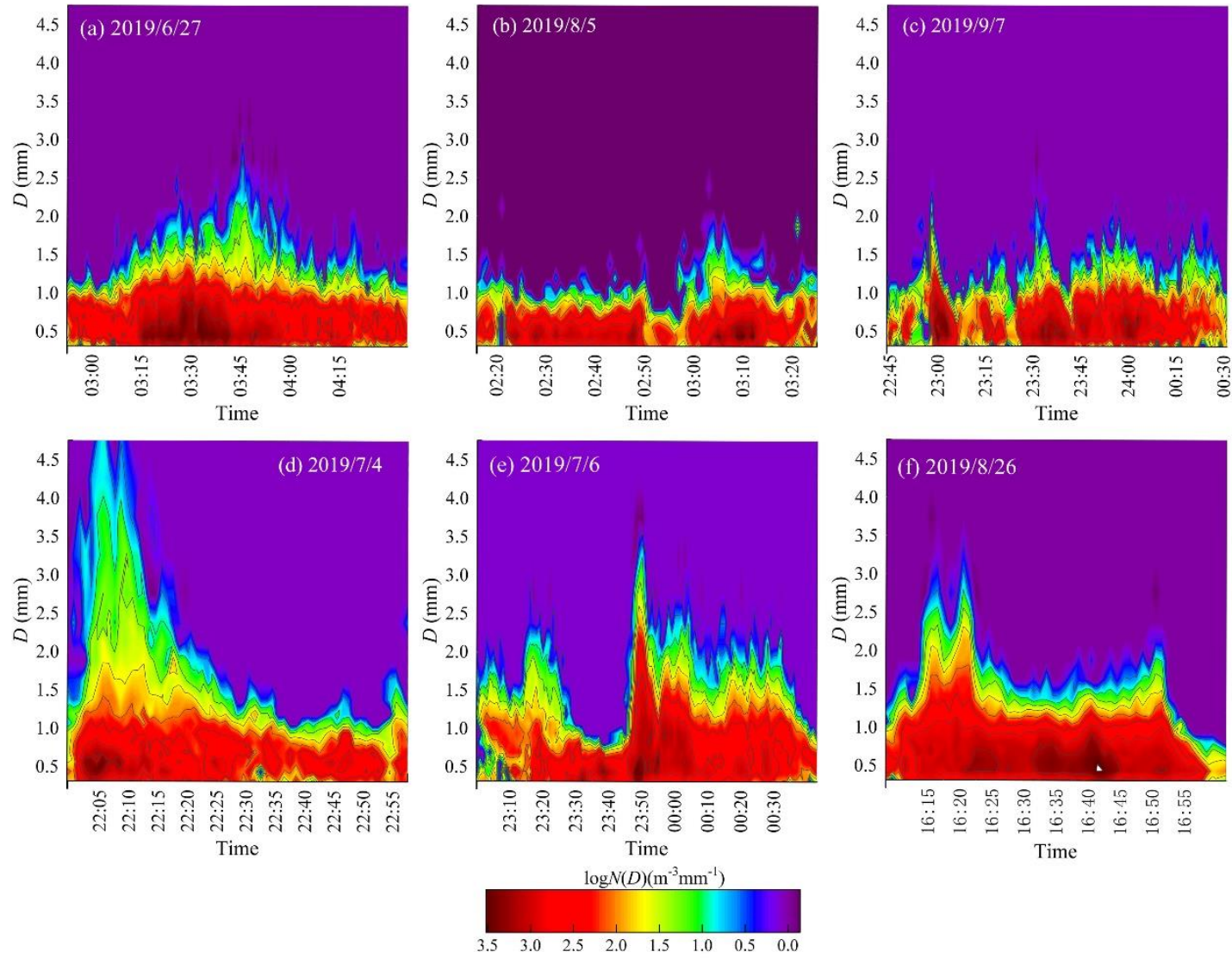

Figure 5. Changes of $N(D)$ over time for precipitation processes of (a) 2019/6/27 3:00-4:43, (b) 2019/8/5 2:16-3:25, (c) 2019/9/7 22:44-2019/9/8 00:31, (d) 2019/7/4 22:02-23:00, (e) 2019/7/6 23:05-2019/7/7 00:48 and (f) 2019/8/26 16:11-17:04. Note: the color bar represents the raindrop concentration on the logarithmic scale (i.e., $\log _{10}(N(D))$.

From Figure 4 and the above analysis, we can see that the microphysical parameters (i.e., $R$, $W$, and $Z$ ) of stratiform precipitation are generally smaller than those of convective precipitation, and the changing trend of the microphysical parameters of stratiform precipitation shows a multi-peak 
structure. From Figure 5, we can see that the spectrum width of stratiform precipitation is smaller than that of convective precipitation. In addition, according to the above-mentioned maximum raindrop concentration value of each precipitation event, the maximum raindrop concentration of stratiform precipitation is smaller than that of convective precipitation.

\subsection{Z-R Relationship}

Generally, the $Z-R$ relationship can be expressed as follows:

$$
Z=a R^{b}
$$

where $Z$ denotes the radar reflectivity factor, $R$ denotes the rainfall intensity, and $a$ and $b$ are coefficients. Normally, for the standard Z-R relationship of the WSR 88D (Next-Generation Weather Radar of the United States), the default coefficients are $a=300$ and $b=1.40$ [43], which have been widely used in weather radar rainfall estimation $[23,24]$.

Based on the data from the above six precipitation events, the two coefficients of the $Z-R$ relationship are quite different. However, for the same type of precipitation, certain regularities can still be summarized. Based on the data derived from stratiform and convective precipitation (Table A1), the results shown in Figure 6 could be obtained using the curve fitting tool in MATLAB. The coefficients of determination were 0.55 and 0.43 for stratiform precipitation and convective precipitation, and the fitting passed the significance test of 0.05 . That indicates that the fitting performance for stratiform precipitation is better than that for convective precipitation. For stratiform precipitations, the values of $a$ (i.e., 186) are lower than for the standard $Z-R$ relationship (i.e., $a=300$ ), and the value of $b$ (i.e., 1.42) is higher than for the standard $Z-R$ relationship (i.e., $b=1.40$ ); by contrast, for convective precipitation, the value of $b$ (i.e., 1.50) is also higher than for the standard $Z-R$ relationship, the value of $a$ (i.e., 154) is lower than that for the standard $Z-R$ relationship. That is attributed to the fact that the exponential factor $b$ is only related to the shape factor $\mu$ of the raindrop size distribution and $b$ increases with the increase of $\mu$ [44]; moreover, the shape factor of convective precipitation (i.e., $\mu=6.28$ ) is higher than the shape factor (i.e., $\mu=5.82$ ) of stratiform precipitation. In contrast, the coefficient $a$ is related to the shape factor $\mu$, total raindrop concentration $N_{T}$, and mass weighted diameter $D_{m}$. The coefficient $a$ increases as $D_{m}$ increases, and decreases as $N_{T}$ increases [44]; moreover, the $N_{T}$ of convective precipitation (i.e., $N_{T}=680.31 \mathrm{~mm}^{-3}$ ) is much larger than the $N_{T}$ of stratiform precipitation (i.e., $N_{T}=288.04 \mathrm{~mm}^{-3}$ ), which results in the coefficient $a$ of convective precipitation being smaller than $a$ of stratiform precipitation. Known from Figure 6, the red line is below the blue line, which means that when $R$ is the same, $Z$ derived from the standard $Z-R$ relationship is less than that value fitted. Therefore, the standard $Z-R$ relationship will underestimate the radar reflectivity factor in this region.
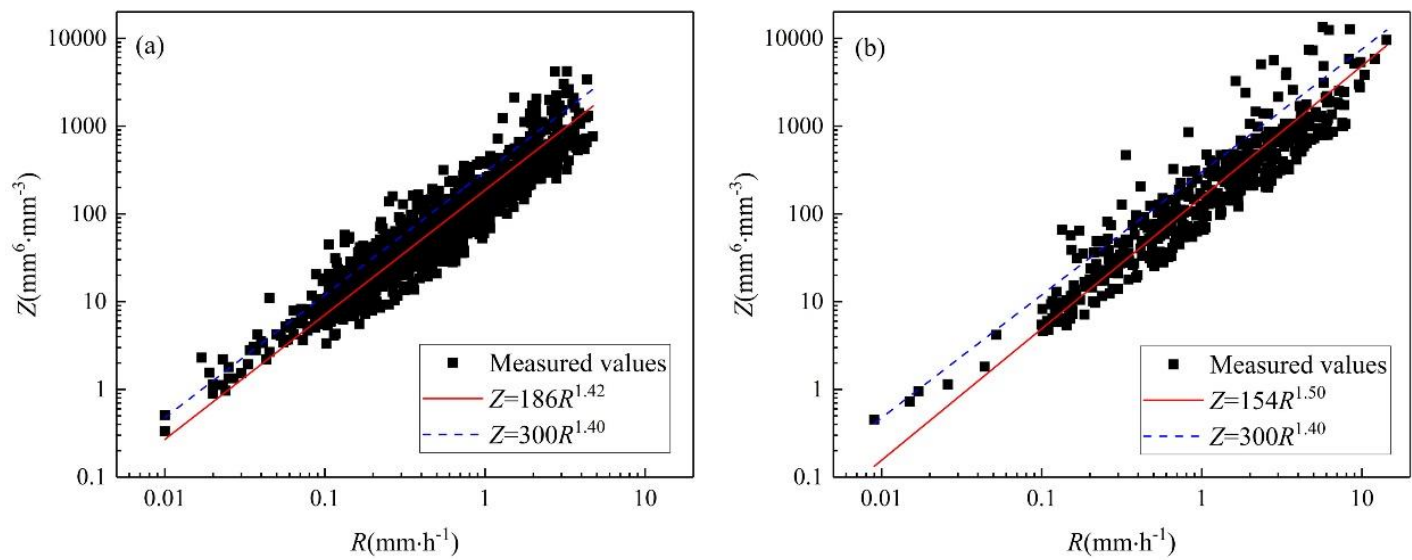

Figure 6. Z-R relationships for (a) stratiform precipitation and (b) convective precipitation. Note: red lines are fitting curves, and blue lines are standard curves. 


\section{Conclusions}

This study analyzes the microphysical characteristics of different types of precipitation in China's inland arid region. Based on the observed data in the study area located in Qinghai-Tibet Plateau during the one-year study period, several new findings are achieved. The major contributions of this study can be described as follows:

First, compared to the exponential distribution, the gamma distribution is the better function to describe the raindrop size distribution in this region, especially for the raindrops with relatively smaller sizes. The large raindrop concentration is mainly distributed at the end of small particles $(0.2-1 \mathrm{~mm})$. Therefore, the fit of small particles determines the fit of the entire distribution. Therefore, for local precipitation, the gamma distribution is better than the exponential distribution.

Second, in this region, for the number of particles, raindrops with diameters of $0.25-1 \mathrm{~mm}$ account for over $85 \%$ of the total contributions for both stratiform precipitation and convective precipitation. For rainfall intensity, raindrops with diameters of $0.25-2 \mathrm{~mm}$ account for over $95 \%$ of the total contributions for both stratiform precipitation and convective precipitation, indicating that the raindrop sizes which contribute most to the rainfall intensity are below $2 \mathrm{~mm}$ for stratiform precipitation and convective precipitation.

Third, the coefficient $a$ over the study region is smaller than for the standard Z-R relationship and the coefficient $b$ over the study region is higher than for the standard $Z-R$ relationship. The standard $Z-R$ relationship will underestimate the radar reflectivity factor in this region. There are some considerable differences with previous studies, the coefficient $a$ values of the $Z-R$ relationship of both types of precipitation are smaller than those of the standard $Z-R$ relationship, but $a$ is larger than that of the Z-R relationship of the Nagqu region of the Tibetan Plateau [29], which is related to the local environment and data processing methods, such as different raindrop concentration, leading to different coefficients.

Furthermore, due to the limited observation period (i.e., one year) and study area, this study only presents the preliminary findings which are different from those in other regions. A longer observation period and larger study area are necessary to validate the obtained results and achieve the more accurate and reliable conclusions. In addition, the obtained results may change in future due to climate change strongly influencing precipitation. Nevertheless, with the awareness of the above limitation, the results reported in this study can provide a new avenue of analyzing the microphysical characteristics of different types of precipitation in inland arid regions, which would be valuable for water resource management and numerical models in such regions.

Author Contributions: Conceptualization, H.X. and J.C.; methodology, H.X.; validation, P.P. and H.S.; formal analysis, P.P.; investigation, P.P. and J.W.; data curation, P.P. and J.W.; writing-original draft preparation, P.P. and H.S.; writing-review and editing, H.S.; supervision, H.X., H.S. and J.C.; project administration, H.X. All authors have read and agreed to the published version of the manuscript.

Funding: This research was funded by the National Key Research and Development Project (grant number 2017YFC0403603), National Natural Science Foundation of China funded project (grant number 91747205, 51909117), and the Natural Science Foundation of Qinghai Province project (grant number 2017-ZJ-911).

Acknowledgments: We are grateful to the students of Qinghai University who carried out the experimental observations under difficult conditions. We are also grateful to the three anonymous reviewers who offered the insightful and constructive comments leading to improvement of this paper.

Conflicts of Interest: The authors declare no conflict of interest. 


\section{Appendix A}

Table A1. Samples of different types of precipitation (S-stratiform, C-convective, and M-mixed).

\begin{tabular}{|c|c|c|c|c|c|c|c|c|}
\hline NO & Date & $\begin{array}{c}\text { Time } \\
(\mathrm{UTC}+8)\end{array}$ & $\begin{array}{c}\text { Number } \\
\text { of } \\
\text { Samples }\end{array}$ & $\begin{array}{l}\text { Maximum } \\
\text { Rainfall } \\
\text { Intensity } \\
\left(\mathrm{mm} \cdot \mathrm{h}^{-1}\right)\end{array}$ & $\begin{array}{l}\text { Standard } \\
\text { Deviation } \\
\left(\mathrm{mm} \cdot \mathrm{h}^{-1}\right)\end{array}$ & $\begin{array}{c}\text { Echo } \\
\text { Intensity } \\
\text { (dBz) }\end{array}$ & $\begin{array}{l}\text { Maximum } \\
\text { Echo (dBz) }\end{array}$ & Type \\
\hline 1 & $2019 / 6 / 27$ & 00:55-01:28 & 34 & 0.67 & 0.11 & 15.11 & 18.97 & $S$ \\
\hline 2 & $2019 / 6 / 27$ & 03:00-04:43 & 103 & 4.31 & 0.87 & 20.37 & 32.35 & S \\
\hline 3 & $2019 / 6 / 29$ & 13:46-14:39 & 54 & 4.42 & 1.06 & 21.76 & 36.19 & $S$ \\
\hline 4 & $2019 / 6 / 29$ & 17:33-18:12 & 40 & 3.85 & 1.1 & 19 & 31.48 & S \\
\hline 5 & $2019 / 6 / 29$ & $19: 22-20: 24$ & 63 & 2.1 & 0.39 & 19.94 & 33.14 & $S$ \\
\hline 6 & $2019 / 7 / 6$ & $20: 48-22: 37$ & 102 & 3.25 & 0.84 & 19.65 & 27.81 & $S$ \\
\hline 7 & 2019/7/10-7/11 & 20:01-05:24 & 539 & 4.73 & 0.71 & 19.39 & 36.25 & $S$ \\
\hline 8 & 2019/7/14 & 18:19-18:50 & 32 & 3.06 & 0.74 & 20.19 & 27.67 & S \\
\hline 9 & 2019/7/17 & 00:15-03:01 & 145 & 3.65 & 0.88 & 16.08 & 32.11 & $S$ \\
\hline 10 & 2019/7/17 & 05:03-05:51 & 46 & 1.7 & 0.47 & 12.75 & 22.09 & $S$ \\
\hline 11 & 2019/7/18 & 09:30-10:16 & 46 & 0.78 & 0.18 & 13.75 & 21.48 & S \\
\hline 12 & $2019 / 7 / 21$ & 07:14-07:57 & 40 & 0.54 & 0.12 & 15 & 20.64 & S \\
\hline 13 & $2019 / 7 / 21$ & 10:18-11:09 & 51 & 0.64 & 0.14 & 13.9 & 18.61 & S \\
\hline 14 & $2019 / 8 / 5$ & 02:16-03:25 & 70 & 0.69 & 0.21 & 11.51 & 22.61 & S \\
\hline 15 & 2019/9/7-9/8 & 22:44-00:31 & 105 & 2.19 & 0.71 & 15.11 & 28.18 & S \\
\hline 16 & $2019 / 9 / 8$ & 14:31-15:14 & 43 & 0.52 & 0.10 & 12.57 & 19.43 & S \\
\hline 17 & $2019 / 9 / 8$ & $15: 36-16: 12$ & 37 & 4.36 & 1.30 & 18.57 & 35.30 & S \\
\hline 18 & 2019/9/19 & 01:11-04:39 & 200 & 1.85 & 0.53 & 14.26 & 25.81 & S \\
\hline 19 & $2019 / 6 / 27$ & 21:06-22:43 & 94 & 10.6 & 2.93 & 25.34 & 36.77 & C \\
\hline 20 & 2019/7/04 & $22: 02-23: 00$ & 57 & 38.69 & 10.43 & 24.36 & 53.81 & C \\
\hline 21 & $2019 / 7 / 06$ & 23:05-00:48 & 99 & 54.32 & 18.33 & 23.75 & 45.15 & C \\
\hline 22 & 2019/7/07 & 11:20-12:08 & 49 & 6.25 & 1.63 & 19.81 & 32.81 & C \\
\hline 23 & 2019/7/11 & 19:25-20:04 & 40 & 5.57 & 1.59 & 20.61 & 31.04 & C \\
\hline 24 & 2019/7/17 & 07:32-08:35 & 64 & 8.34 & 2.43 & 21.04 & 37.63 & C \\
\hline 25 & $2019 / 8 / 26$ & 16:11-17:04 & 53 & 14.28 & 3.98 & 22.48 & 39.80 & $\mathrm{C}$ \\
\hline 26 & 2019/9/11 & 20:34-21:06 & 33 & 6.23 & 2.21 & 21.60 & 41.28 & $\mathrm{C}$ \\
\hline 27 & $2019 / 6 / 27$ & 18:38-19:34 & 57 & 5.49 & 1.43 & 20.63 & 29.63 & M \\
\hline 28 & 2019/7/13 & $20: 47-21: 23$ & 37 & 7.17 & 0.85 & 25.08 & 30.77 & M \\
\hline 29 & 2019/8/7-8/8 & 23:08-02:31 & 184 & 7.86 & 1.22 & 19.56 & 38.84 & M \\
\hline
\end{tabular}

\section{References}

1. Kisi, O.; Sanikhani, H. Prediction of long-term monthly precipitation using several soft computing methods without climatic data. Int. J. Climatol. 2015, 35, 4139-4150. [CrossRef]

2. Shi, H.Y.; Chen, J.; Li, T.J.; Wang, G.Q. A new method for estimation of spatially distributed rainfall through merging satellite observations, raingauge records, and terrain digital elevation model data. J. Hydro-Environ. Res. 2020, 28, 1-14. [CrossRef]

3. Shi, H.Y.; Li, T.J.; Wei, J.H. Evaluation of the gridded CRU TS precipitation dataset with the point raingauge records over the Three-River Headwaters region. J. Hydrol. 2017, 548, 322-332. [CrossRef]

4. Liu, S.N.; Shi, H.Y.; Sivakumar, B. Socioeconomic drought under growing population and changing climate: A new index considering the resilience of a regional water resources system. J. Geophys. Res. Atmos. 2020, 125. [CrossRef]

5. Liu, S.N.; Shi, H.Y. A recursive approach to long-term prediction of monthly precipitation using genetic programming. Water Resour. Manag. 2019, 33, 1103-1121. [CrossRef]

6. Caracciolo, C.; Napoli, M.; Porcu, F.; Prodi, F.; Dietrich, S.; Zanchi, C.; Orlandini, S. Raindrop size distribution and soil erosion. J. Irrig. Drain. Eng. 2012, 138, 461-469. [CrossRef]

7. Yau, M.K.; Rogers, R.R. A Short Course in Cloud Physics; Elsevier: Amsterdam, The Netherlands, 1996.

8. Radhakrishna, B.; Rao, T.N. Statistical characteristics of multipeak raindrop size distributions at the surface and aloft in different rain regimes. Mon. Weather Rev. 2009, 137, 3501-3518. [CrossRef] 
9. Zhang, G.; Sun, J.; Brandes, E.A. Improving parameterization of rain microphysics with disdrometer and radar observations. J. Atmos. Sci. 2006, 63, 1273-1290. [CrossRef]

10. Scheleusener, P.E. Drop Size Distribution and Energy of Falling Raindrops from a Medium Pressure Irrigation Sprinkler. Ph.D. Thesis, Michigan State University, East Lansing, MI, USA, 1967.

11. Hall, M.J. Use of the stain method in determining of the dropsize distribution of coarse liquid sprays. Trans. ASAE 1970, 13, 33-37. [CrossRef]

12. Ulbrich, C.W.; Atlas, D. Rainfall microphysics and radar properties: Analysis methods for drop size spectra. J. Appl. Meteorol. 1998, 37, 912-923. [CrossRef]

13. Ulbrich, C.W.; Atlas, D. Microphysics of raindrop size spectra: Tropical continental and maritime storms. J. Appl. Meteorol. Climatol. 2007, 46, 1777-1791. [CrossRef]

14. Steiner, M.; Smith, J.A. Scale dependence of radar-rainfall rates-an assessment based on raindrop spectra. J. Hydrometeorol. 2004, 5, 1171-1180. [CrossRef]

15. Williams, C.R.; Bringi, V.N.; Carey, L.D.; Chandrasekar, V.; Gatlin, P.N.; Haddad, Z.S.; Meneghini, R.; Munchak, S.J.; Nesbitt, S.W.; Petersen, W.A.; et al. Describing the shape of raindrop size distributions using uncorrelated raindrop mass spectrum parameters. J. Appl. Meteorol. Climatol. 2014, 53, 1282-1296. [CrossRef]

16. Gamache, J.F.; Houze, R.A., Jr. Mesoscale air motions associated with a tropical squall line. Mon. Weather Rev. 1982, 110, 118-135. [CrossRef]

17. Johnson, R.H.; Hamilton, P.J. The relationship of surface pressure features to the precipitation and air flow structure of an intense mid-latitude squall line. Mon. Weather Rev. 1988, 116, 1444-1472. [CrossRef]

18. Bringi, V.N.; Chandrasekar, V.; Hubbert, J.; Gorgucci, E.; Randeu, W.L.; Schoenhuber, M. Raindrop size distribution in different climatic regimes from disdrometer and dual-polarized radar analysis. J. Atmos. Sci. 2003, 60, 354-365. [CrossRef]

19. Liu, H.Y.; Lei, H.C. Characteristics of rain from stratiform versus convective cloud based on surface raindrop data. Chin. J. Atmos. Sci. 2006, 30, 693-702. (In Chinese)

20. Marzano, F.S.; Cimini, D.; Montopoli, M. Investigating precipitation microphysics using groundbased microwave remote sensors and disdrometer data. Atmos. Res. 2010, 97, 583-600. [CrossRef]

21. Chen, B.; Yang, J.; Pu, J. Statistical characteristics of raindrop size distribution in the Meiyu season observed in Eastern China. J. Meteorol. Soc. Jpn. 2013, 91, 215-227. [CrossRef]

22. Chandrasekar, V.; Bringi, V.N. Simulation of radar re-flectivity and surface measurements of rainfall. J. Atmos. Ocean. Technol. 1987, 4, 464-478. [CrossRef]

23. Smith, J.A.; Seo, D.J.; Baeck, M.L.; Hudlow, M.D. An intercomparison study of NEXRAD precipitation estimates. Water Resour. Res. 1996, 32, 2035-2045. [CrossRef]

24. Young, C.B.; Nelson, B.R.; Bradley, A.A.; Smith, J.A.; Peters-Lidard, C.D.; Kruger, A.; Baeck, M.L. An evaluation of NEXRAD precipitation estimates in complex terrain. J. Geophys. Res. Atmos. 1999, 104, 19691-19703. [CrossRef]

25. Chapon, B.; Delrieu, G.; Gosset, M.; Boudevillain, B. Variability of rain drop size distribution and its effect on the Z-R relationship: A case study for intense Mediterranean rainfall. Atmos. Res. 2008, 87, 52-65. [CrossRef]

26. Verrier, S.; Barthes, L.; Mallet, C. Theoretical and empirical scale dependency of Z-R relationships: Evidence, impacts, and correction. J. Geophys. Res. Atmos. 2013, 118, 7435-7449. [CrossRef]

27. Hasan, M.M.; Sharma, A.; Johnson, F.; Mariethoz, G.; Seed, A. Correcting bias in radar Z-R relationships due to uncertainty in point rain gauge networks. J. Hydrol. 2014, 519, 1668-1676. [CrossRef]

28. Fang, X.; Shao, A.M.; Yue, X.J.; Liu, W.C. Statistics of the Z-R relationship for strong convective weather over the Yangtze-Huaihe river basin and its application to radar reflectivity data assimilation for a heavy rain event. J. Meteorol. Res. 2018, 32, 598-611. [CrossRef]

29. Wu, Y.; Liu, L. Statistical characteristics of raindrop size distribution in the Tibetan Plateau and Southern China. Adv. Atmos. Sci. 2017, 34, 727-736. [CrossRef]

30. Xi, Y.; Miao, C.Y.; Wu, J.W.; Duan, Q.; Lei, X.; Li, H. Spatiotemporal changes in extreme temperature and precipitation events in the Three-Rivers Headwater region, China. J. Geophys. Res. Atmos. 2018, 123. [CrossRef]

31. Shi, H.Y.; Li, T.J.; Wei, J.H.; Fu, W.; Wang, G. Spatial and temporal characteristics of precipitation over the Three-River Headwaters region during 1961-2014. J. Hydrol. Reg. Stud. 2016, 6, 52-65. [CrossRef]

32. Liang, L.Q.; Li, L.J.; Liu, C.M.; Cuo, L. Climate change in the Tibetan Plateau Three Rivers Source region: 1960-2009. Int. J. Climatol. 2013, 33, 2900-2916. [CrossRef] 
33. Cao, L.G.; Pan, S.M. Changes in precipitation extremes over the "Three-River Headwaters" region, hinterland of the Tibetan Plateau, during 1960-2012. Quat. Int. 2014, 321, 105-115. [CrossRef]

34. Duan, A.M.; Hu, J.; Xiao, Z.X. The Tibetan Plateau summer monsoon in the CMIP5 simulations. J. Clim. 2013, 26, 7747-7766. [CrossRef]

35. Loffler-Mang, M.; Joss, J. An optical distrometer for measuring size and velocity of hydrometers. J. Atmos. Ocean. Technol. 2000, 17, 130-139. [CrossRef]

36. Battaglia, A.; Rustemeier, E.; Tokay, A.; Blahak, U.; Simmer, C. PARSIVEL snow observations: A critical assessment. J. Atmos. Ocean. Technol. 2010, 27, 333-344. [CrossRef]

37. Tokay, A.; Wolff, D.B.; Petersen, W.A. Evaluation of the new version of the laser-optical disdrometer, OTT Parsivel2 ${ }^{2}$. J. Atmos. Ocean. Technol. 2014, 31, 1276-1288. [CrossRef]

38. Tokay, A.; Petersen, W.A.; Gatlin, P.; Wingo, M. Comparison of raindrop size distribution measurements by collocated disdrometers. J. Atmos. Ocean. Technol. 2013, 30, 1672-1690. [CrossRef]

39. Tokay, A.; Bashor, P.G. An experimental study of small-scale variability of raindrop size distribution. J. Appl. Meteorol. 2010, 49, 2348-2365. [CrossRef]

40. Feingold, G.; Levin, Z. The lognormal fit to raindrop spectra from frontal convective clouds in Israel. J. Appl. Meteorol. 1986, 25, 1346-1364. [CrossRef]

41. Marshall, J.S.; Palmer, W.M. The distribution of raindrops with size. J. Meteorol. 1948, 5, 165-166. [CrossRef]

42. Williams, C.R.; Gage, K.S. Raindrop size distribution variability estimated using ensemble statistics. Ann. Geophys. 2009, 27, 555-567. [CrossRef]

43. Fulton, R.A.; Breidenbach, J.P.; Seo, D.J.; Miller, D.A.; O'Bannon, T. The WSR-88D rainfall algorithm. Weather Forecast. 1998, 13, 377-395. [CrossRef]

44. Feng, L.; Chen, B.J. The radar reflectivity-rainrate relationships as inferred from ground-based raindrop spectra by GBPP-100 Probe. J. Meteorol. Sci. 2009, 29, 2192-2198.

(C) 2020 by the authors. Licensee MDPI, Basel, Switzerland. This article is an open access article distributed under the terms and conditions of the Creative Commons Attribution (CC BY) license (http://creativecommons.org/licenses/by/4.0/). 